\title{
Role of morphometry in determining the feeding success of small freshwater fish species: Multivariate analysis of Amblypharyngodon mola, Puntius ticto, and Esomus danricus
}

\author{
Sudarshana Nandi, Surjya Kumar Saikia
}

Received - 04 March 2015/Accepted - 03 June 2015. Published online: 30 June 2015; @Inland Fisheries Institute in Olsztyn, Poland Citation: Nandi S., Saikia S.K. 2015 - Role of morphometry in determining the feeding success of small freshwater fish species: Multivariate analysis of Amblypharyngodon mola, Puntius ticto, and Esomus danricus - Arch. Pol. Fish. 23: 79-90.

\begin{abstract}
Factor and multiple regression analysis were used to extract the morphometric variables that contributed to feeding success in three small freshwater fishes. Of the first two factors, factor 1 , showed high loading of gut weight (GW), length of the upper (UJ), and lower jaws (LJ) in mola, Amblypharyngodon mola (Hamilton), and GW and vertical mouth opening (VMO) in punti, Puntius ticto (Hamilton). In darikana, Esomus danricus (Hamilton), GW, horizontal mouth opening (HMO), and VMO were highly loaded on factor 2. Gut length (GL) was closely associated with GW of all three species. Subsequently, variables with high loading on factors 1 or 2 were subjected to multiple regression analysis to observe their effect on feeding success, considering GW as the dependent variable and the extracted variables as the independent variable. In A. mola, HMO and GL influenced GW, whereas in P. ticto, only GL determined GW in the fish. In E. danricus, GL, VMO, and HMO exerted a low effect on GW. Exceptionally, the present study suggested that feeding success in small fishes is largely determined by UJ, LJ, and GL or mouth openings.
\end{abstract}

Keywords: morphoecology, feeding strategy, regression analysis, gape limitation, feeding ecology

S. Nandi, S.K Saikia [ $\left.\Xi^{\circ}\right]$

Aquatic Ecology and Fish Biology Laboratory

Department of Zoology

Visva Bharati University, Santiniketan, Bolpur,

West Bengal, India - 731235

e-mail: surjyasurjya@gmail.com, tel: +91 9475849511

\section{Introduction}

Morphological features linked to prey capture and intake evolved to maximize feeding performance and can be strongly correlated with diet (Wikramanayake 1990, Piet 1998, Hugueny and Pouilly 1999). In fish, this correlation is highly prevalent (Dabrowski and Bardega 1984). Most studies on the role of morphology in fish prey selectivity were conducted on carnivorous fishes at higher trophic levels (Nilsson and Brönmark 2000, Conley and Hopkins 2004, Dean and Motta 2004). Small fishes (total length $<25 \mathrm{~cm}$ ), especially freshwater endemic species, hardly maintain plasticity in feeding, hence, they are vulnerable to food limitations. No extensive studies on the shortor long-term feeding success of this small fish group have yet been performed. With their co-occurrence with large fish species in regulated and unregulated aquatic systems, feeding success could be a major axis through food partitioning (Ross 1986), which could thereby enable survival and growth in fishes that have advantageous features. Slight variation in morphology results in large differences in feeding success, and it strongly influences diet selection (Wainwright and Richard 1995, Carroll et al. 2004).

A. mola, P. ticto, and E. danricus are small freshwater fish that thrive in shallow water bodies and are

(c) Copyright by Stanisław Sakowicz Inland Fisheries Institute in Olsztyn.

C 2015 Author(s). This is an open access article licensed under the Creative Commons Attribution-NonCommercial-NoDerivs License

(http://creativecommons.org/licenses/by-nc-nd/3.0/). 
commonly noted as indigenous to India, Bangladesh, Pakistan, Myanmar, Nepal, and Bhutan (Sen 1985, Talwar and Jhingran 2001). With the exception of $A$. mola (Mamun et al. 2004, Mondol et al. 2013, Nandi and Saikia 2015), details about the feeding biology of these fishes remains unknown. In IUCN databases, these three fishes are accorded the least importance, although unreported cases of vast loss of these species' habitats have occurred in recent times. The present study attempted to explain whether the feeding success of small microphagous fish depends on some principles of the morphometric arrangement of their mouths, as well as on other associated structures. In this study, we analyzed nine different morphometric measurements of these three common, co-occurring small freshwater fish species for any ecomorphological correlation with feeding success. Following Pepin et al. (2015), gut weight was considered the best index of short-term feeding success, showing the biomass captured immediately from the surroundings.

This objective was accomplished using multivariate analysis techniques, especially multivariate factor analysis and multiple regression analysis. Multiple factor analysis was used to investigate factors that are highly correlated and to determine the feeding activity of the fish. This was followed by multiple regression analysis with highly correlated variables extracted through multiple factor analysis, and it was employed to explain the degree of the dependence of feeding success of these fishes based on their morphometry. This study also demonstrated the use of multivariate statistics to explain how morphometric variables contribute to feeding success in small fishes.

\section{Materials and methods}

\section{Morphometric data}

All the fishes were collected from freshwater ponds $\left(23.6700^{\circ} \mathrm{N}, 87.7200^{\circ} \mathrm{E}\right)$ around Bolpur, Birbhum District, West Bengal, India, during 2013-2014 (Fig. 1). The fishes were preserved on ice

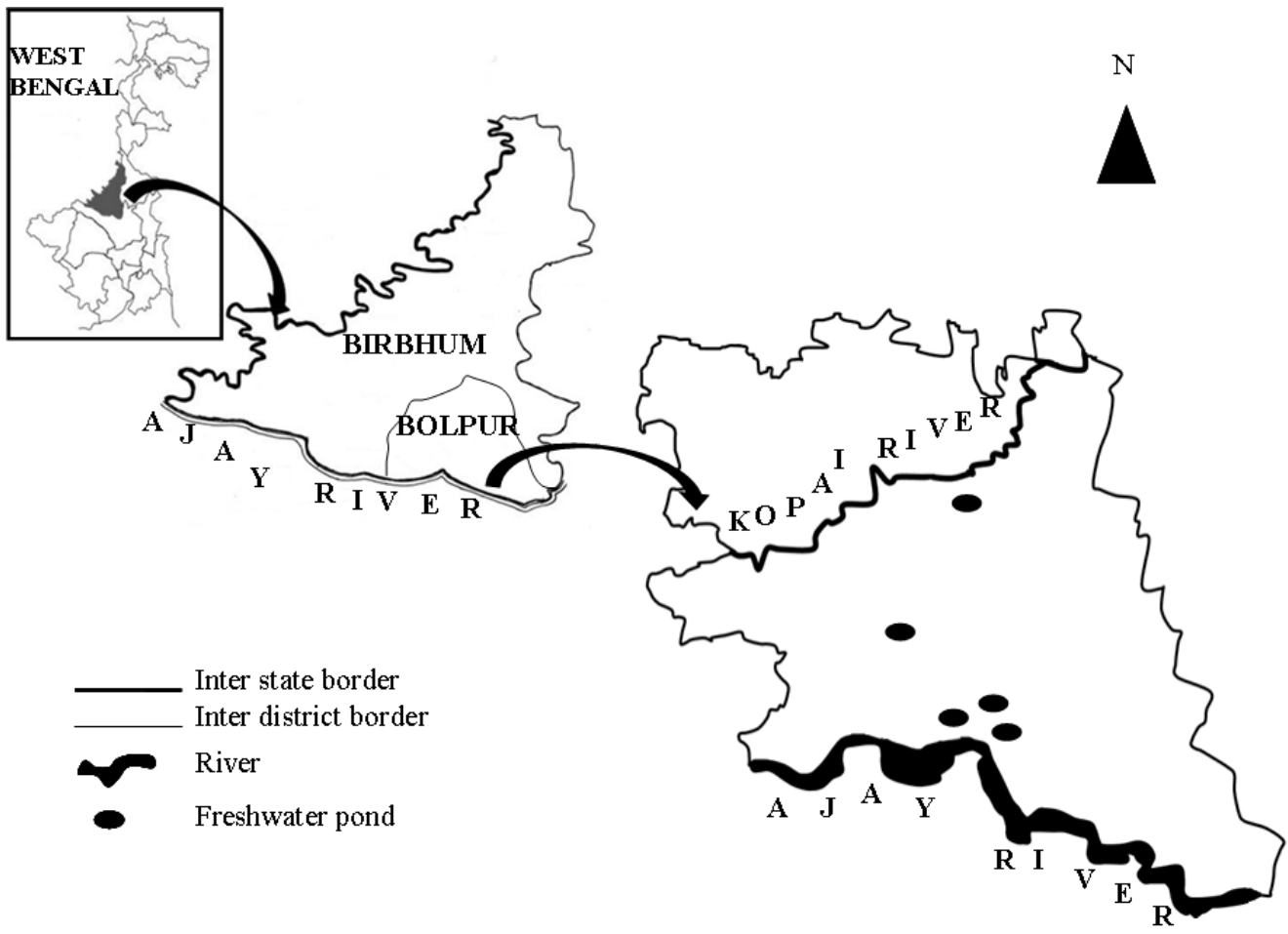

Figure 1. Location of freshwater ponds in Bolpur, Birbhum district, West Bengal, India, from which three small freshwater fishes, $A$. mola, P. ticto, and E. danricus, were sampled. The map is not to scale. 
immediately after collection. Morphometric variables were measured without distorting the fish body shape. The length measurements (total length, TL; length of upper jaw, LU; length of lower jaw, LJ) were recorded using a scientific scale (KHYATI) to the nearest mm (Chattopadhyay et al. 2014). The horizontal mouth opening (HMO) and vertical mouth opening (VMO) were measured up to the maximum jaw extension using slide calipers. The gut was dissected out, carefully uncoiled to stretch it out on a Petri dish, and the gut length (GL) was measured. Guts with food content were weighed to the nearest mg on a calibrated electronic scale and subtracted from the empty gut to obtain the gut weight (GW). The mouth area (MA) and gape size (GS) was computed following the procedure in Erzini et al. (1997) and Ponton and Müller (1990).

\section{Statistical analysis}

Two statistical software programs, Minitab 11 and SPSS 16.0, were used to compute all the statistical analysis throughout the study. Standard Deviation (SD) was computed to explain the mean as the accurate point estimate. The reproducibility of the mean was explained within $95 \%$ confidence intervals.

All the data were checked for normality before proceeding to a specific statistical parametric analysis. Multivariate factorial analysis, used as a statistical tool for factor reduction, can simplify a complex data set by identifying one or more underlying factors that can explain the nature and dimension of the association with variability. Although different scaling methods are used to fix the factors, we performed a screen plot for factor reduction. Only those factors which explained a maximum number of variations (\%) and the nature of the association among the variables and cluster recognition were considered to be of a high degree. A correlation matrix was used to extract the factors from all the variables selected. A varimax rotation was applied in order to maximize the variance of the squared loadings and to reduce the relatively unimportant components. However, before proceeding, the Kaiser-Meyer-Olkin measure and Bartlett's test of sphericity were performed. If the Kaiser-Meyer-Olkin value was $>0.7$ and the Bartlett's test of sphericity recorded $\mathrm{p}<0.05$, the analysis proceeded. Extracted variables obtained through factorial reduction were used for regression analysis. Post-hoc statistical power (P) was determined for all the regression analyses using the statistical software G-power 3.1. Type I $(\alpha)$ and Type II (1- $\beta)$ error rates were fixed at $5 \%(\mathrm{p} \leq 0.05)$ and $80 \%(\mathrm{P} \leq 0.08)$, respectively, and the actual $\mathrm{p}$ and $\mathrm{P}$ values were mentioned wherever necessary. The multicollinearity of the regressed variables was corrected by removing the factors with VIF $>10.0$. Throughout the study, the gut weight (or gut fullness) of the fish was considered as a function of its feeding capability (Conley and Hopkins 2004, Pepin et al. 2015); hence, mean gut weight values were used as the dependent variables and the mean values of the other variables, which correlated strongly to gut weight under a factor, were used as the independent variables.

\section{Results}

The descriptive statistics of the morphometric measurements of all the three species of fishes are shown in Table 1. The Kolmogorov-Smirnov normality test $(\mathrm{p}>$ $0.05)$ was performed for the morphometric data of $A$. mola and $E$. danricus (sample size $>50$ ). Similarly, the Shapiro-Wilk normality test was performed for $P$. ticto (sample size < 50). All results showed that the $\alpha$ error rate was approximately normal for all the variables considered, without the need for any data transformation for parametric statistical tests. The computation of a $95 \%$ confidence limit also showed very low variation suggesting the correctness of the point estimates (means) of the data generated during the study.

\section{Factorial analysis of the variables}

The screen plots of all three species for nine variables resulted in the first two factors explaining the highest variability among the data. In the case of $P$. ticto, the first two factors explained variation of $84.0 \%$ (43.5 
Table 1

Descriptive statistics of three small freshwater fish species, $A$. mola $(\mathrm{n}=60)$, E. danricus $(\mathrm{n}=76)$ and $P$. ticto $(\mathrm{n}=43)$. TL - total length (mm), GW - gut weight (g), LJ - lower jaw length (mm), UJ - upper jaw length (mm), HMO - horizontal mouth opening $\left(\mathrm{mm}^{2}\right)$, VMO - vertical mouth opening $\left(\mathrm{mm}^{2}\right)$, GL - gut length $(\mathrm{mm})$, MA - mouth area $\left(\mathrm{mm}^{2}\right)$, GS - gape size $\left(\mathrm{mm}^{2}\right), \mathrm{M}-\mathrm{Mean}$, SE - Standard Error, CI - Confidence Interval, NM - normality

\begin{tabular}{clllllllll}
\hline \hline & TL & GW & UJ & LJ & HMO & VMO & GL & MA & GS \\
\hline \hline A. mola & & & & & & & & & \\
M & 7.80 & 0.08 & 0.33 & 0.44 & 0.44 & 0.41 & 26.30 & 0.14 & 0.47 \\
SE & 0.19 & 0.01 & 0.01 & 0.01 & 0.02 & 0.01 & 1.22 & 0.01 & 0.02 \\
CI & $7.4-8.1$ & $0.07-0.10$ & $0.31-0.36$ & $0.41-0.47$ & $0.41-0.47$ & $0.38-0.43$ & $23.9-28.7$ & $0.13-0.16$ & $0.44-0.50$ \\
NM & $>0.055$ & $>0.19$ & $>0.15$ & $>0.15$ & $>0.15$ & $>0.15$ & $>0.15$ & $>0.057$ & $>0.15$ \\
E. danricus & & & & & & & & \\
M & 5.93 & 0.05 & 0.23 & 0.32 & 0.33 & 0.42 & 14.37 & 0.11 & 0.32 \\
SE & 0.06 & 0.002 & 0.01 & 0.01 & 0.01 & 0.01 & 0.42 & 0.004 & 0.10 \\
CI & $5.80-6.05$ & $0.047-0.058$ & $0.209-0.243$ & $0.30-0.33$ & $0.312-0.340$ & $0.406-0.437$ & $13.5-15.2$ & $0.103-0.119$ & $0.30-0.34$ \\
NM & 0.065 & 0.056 & $>0.15$ & $>0.15$ & $>0.15$ & $>0.15$ & $>0.058$ & $>0.15$ & $>0.10$ \\
P. ticto & & & & & & & & 0.15 \\
M & 8.01 & 0.18 & 0.35 & 0.25 & 0.37 & 0.46 & 21.01 & 0.14 & 0.50 \\
SE & 0.21 & 0.01 & 0.02 & 0.02 & 0.01 & 0.02 & 0.73 & 0.01 & 0.03 \\
CI & $7.6-8.4$ & $0.16-0.20$ & $0.32-0.39$ & $0.22-0.28$ & $0.34-0.39$ & $0.43-0.50$ & $19.6-22.4$ & $0.12-0.16$ & $0.45-0.50$ \\
NM & $>0.0545$ & $>0.057$ & $>0.10$ & $>0.10$ & $>0.10$ & $>0.10$ & $>0.057$ & $>0.058$ & $>0.10$ \\
\hline \hline
\end{tabular}

Table 2

Factor analysis (varimax rotation) of three small fish species: $A$. mola $(\mathrm{n}=60)$, E. danricus $(\mathrm{n}=76), P$. ticto $(\mathrm{n}=43)$. GW - gut weight, UJ - upper jaw length, LJ - lower jaw length, HMO - horizontal mouth opening, VMO - vertical mouth opening, GL - gut length

\begin{tabular}{llllllllll}
\hline \hline \multirow{2}{*}{ Variable } & A. mola & \multicolumn{3}{c}{ E. danricus } & \multicolumn{3}{c}{ P. ticto } \\
\cline { 2 - 10 } & Factor 1 & Factor 2 & Communality & Factor 1 & Factor 2 & Communality & Factor 1 & Factor 2 & Communality \\
\hline \hline GW & 0.834 & 0.267 & 0.766 & -0.018 & 0.819 & 0.672 & 0.859 & 0.284 & 0.819 \\
UJ & 0.918 & -0.252 & 0.907 & 0.932 & 0.202 & 0.909 & 0.417 & 0.871 & 0.933 \\
LJ & 0.917 & -0.218 & 0.888 & 0.948 & 0.209 & 0.941 & 0.326 & 0.893 & 0.904 \\
HMO & 0.705 & -0.627 & 0.890 & 0.539 & 0.743 & 0.843 & 0.611 & 0.646 & 0.791 \\
VMO & -0.074 & -0.935 & 0.880 & 0.535 & 0.709 & 0.789 & 0.791 & 0.387 & 0.776 \\
GL & 0.957 & 0.086 & 0.922 & 0.349 & 0.798 & 0.759 & 0.769 & 0.473 & 0.815 \\
Variance & 3.795 & 1.457 & 5.253 & 2.465 & 2.447 & 4.913 & 2.609 & 2.428 & 5.037 \\
\% Var. & 0.633 & 0.243 & 0.876 & 0.411 & 0.408 & 0.819 & 0.435 & 0.405 & 0.840 \\
Eigenvalue & 3.897 & 1.355 & 0.403 & 3.887 & 1.026 & 0.607 & 4.484 & 0.553 & 0.428 \\
Proportion & 0.650 & 0.226 & 0.067 & 0.648 & 0.171 & 0.101 & 0.747 & 0.092 & 0.071 \\
Cumulative & 0.650 & 0.876 & 0.943 & 0.648 & 0.819 & 0.920 & 0.747 & 0.840 & 0.911 \\
\hline \hline
\end{tabular}

Kaiser-Meyer-Olkin Measure of Sampling Adequacy (KMO) and p value of Bartlett's Test of Sphericity: A. mola KMO = 0.74, $\mathrm{p}<$ 0.000 , E. danricus $\mathrm{KMO}=0.74, \mathrm{p}<0.000$, P. ticto $\mathrm{KMO}=0.81, \mathrm{p}<0.000$

and $40.5 \%$, respectively), while in E. danricus it was 81.9\% (41.1 and 40.8\%, respectively). However, in $A$. mola, it was $87.6 \%$, with factor 1 explaining $63.3 \%$ of total variation (Table 2). The factor reduction with varimax rotation was subsequently applied to the data of each fish species for the first two factors, each representing a cluster of interrelated variables within the data set. The rotated factor loadings, communalities, and percentage of variance explained by each factor are presented in Table 2 . 
Table 3

Coefficients of different variables regressed on gut weight (GW) of small freshwater fish species A. mola (n = 60). Regression analysis were shown for all independent morphometric variables (a), independent morphometric variables without GL (b), and independent variable GL only (c). UJ - upper jaw length, LJ - lower jaw length, HMO - horizontal mouth opening, GL - gut length

\begin{tabular}{|c|c|c|c|c|c|c|c|c|c|c|}
\hline & Predictor & Coefficient & $\mathrm{SD}$ & $\mathrm{T}$ & $\mathrm{p}$ & VIF & $\mathrm{R}^{2}$ & $\mathrm{R}^{2}$ (Adjusted) & Cohen's $\mathrm{f}^{2}$ & $\mathrm{P}$ \\
\hline \multirow[t]{5}{*}{ (a) } & Constant & -0.034 & 0.022 & -1.55 & $>0.05$ & & & & & \\
\hline & UJ & 0.062 & 0.143 & 0.43 & $>0.05$ & 8.6 & & & & \\
\hline & $\mathrm{LJ}$ & 0.191 & 0.096 & 1.99 & $>0.05$ & 5 & $65.50 \%$ & $63.00 \%$ & 1.7 & 1 \\
\hline & HMO & -0.175 & 0.076 & -2.31 & $<0.05$ & 4.1 & & & & \\
\hline & GL & 0.003 & 0.001 & 3.36 & $<0.05$ & 5.5 & & & & \\
\hline \multirow[t]{4}{*}{ (b) } & Constant & -0.065 & 0.021 & -3.04 & $<0.05$ & & & & & \\
\hline & HMO & -0.292 & 0.073 & -3.99 & $<0.05$ & 3.3 & $58.50 \%$ & $56.30 \%$ & 1.28 & 1 \\
\hline & UJ & 0.362 & 0.122 & 2.96 & $<0.05$ & 5.3 & & & & \\
\hline & $\mathrm{LJ}$ & 0.350 & 0.091 & 3.83 & $<0.05$ & 3.8 & & & & \\
\hline \multirow[t]{2}{*}{ (c) } & Constant & -0.028 & 0.012 & -2.24 & $<0.05$ & & $59.90 \%$ & $59.90 \%$ & 1.49 & 1 \\
\hline & GL & 0.004 & 0.000 & 9.44 & $<0.05$ & & & & & \\
\hline
\end{tabular}

Communalities for the variables in all three fishes were less than 1.0. Except for A. mola, the first two factors of E. danricus and P. ticto showed almost equal variability with eigenvalues higher than 1.0 .

\section{Multiple regression analysis}

After the functionally correlated variables were extracted with factor analysis, the variables highly loaded with GW were considered for regression analysis. Other than GW, all the other variables highly loaded on that factor were considered as independent variables determining GW. The results of the regression coefficients, their SD values, VIF, $\mathrm{R}^{2}$, adjusted $\mathrm{R}^{2}$, Cohen's $\mathrm{f}^{2}$, and $\mathrm{P}$ of the test for all these three species are shown in Tables 3 and 4 . The $P$ (or $1-\beta$ ) of the tests for the regression analysis were sufficiently large, validating statistically insignificant Type II error of the analysis. In the case of $A$. mola, the independent variables predicting GW were UJ, LJ, GL, and HMO. For $E$. danricus, these were $\mathrm{HMO}, \mathrm{VMO}$, and GL, while for P. ticto, they were VMO and GL. In A. mola, the independent variables explained $63 \%$ of variation in GW. In this species, the regression of GL and HMO on GW was found to be statistically significant with low VIF

Table 4

Coefficients of multiple linear regression of different variables on gut weight (GW) of small freshwater fish species, E. danricus (n $=76)$ and $P$. ticto $(\mathrm{n}=43)$. HMO - horizontal mouth opening, VMO - vertical mouth opening, GL - gut length

\begin{tabular}{|c|c|c|c|c|c|c|c|c|c|}
\hline Predictor & Coefficient & $\mathrm{SD}$ & $\mathrm{T}$ & $\mathrm{p}$ & VIF & $\mathrm{R}^{2}$ & $\mathrm{R}^{2}$ (Adjusted) & Cohen's $f^{2}$ & $\mathrm{P}$ \\
\hline \multicolumn{10}{|l|}{ E. danricus } \\
\hline Constant & -0.004 & 0.014 & -0.26 & $>0.05$ & & & & & \\
\hline HMO & 0.258 & 0.073 & 3.51 & $<0.05$ & 3.7 & $35.2 \%$ & $32.5 \%$ & 0.48 & 0.99 \\
\hline VMO & -0.152 & 0.067 & -2.28 & $<0.05$ & 4.5 & & & & \\
\hline GL & 0.003 & 0.001 & 2.63 & $<0.05$ & 2.4 & & & & \\
\hline \multicolumn{10}{|l|}{ P. ticto } \\
\hline Constant & -0.099 & 0.037 & -2.67 & $<0.05$ & & & & & \\
\hline HMO & 0.133 & 0.136 & 0.97 & $>0.05$ & 2.6 & $60.9 \%$ & $57.9 \%$ & 1.37 & 1.00 \\
\hline VMO & 0.101 & 0.107 & 0.94 & $>0.05$ & 2.7 & & & & \\
\hline GL & 0.009 & 0.003 & 3.51 & $<0.05$ & 2.3 & & & & \\
\hline
\end{tabular}



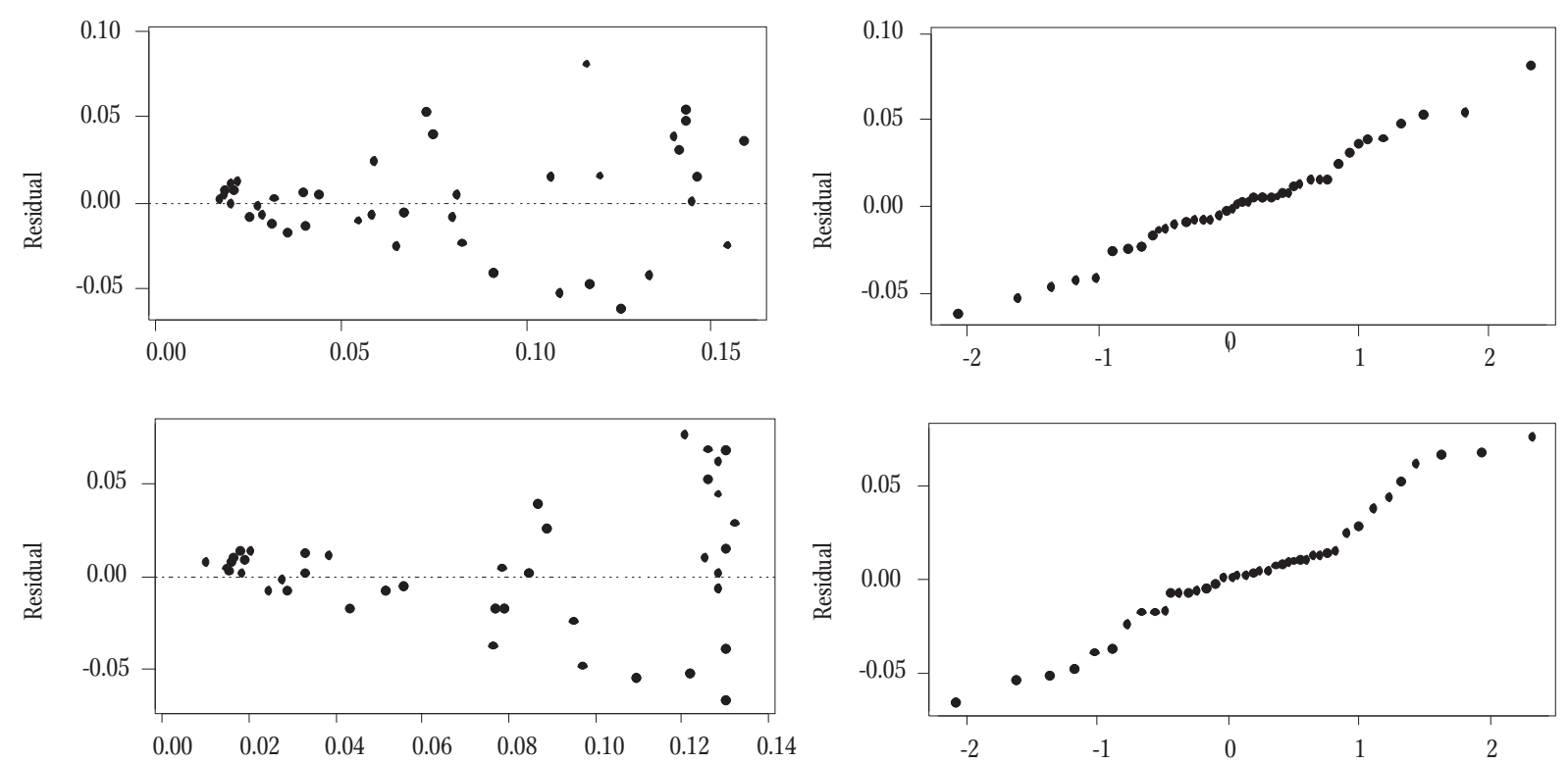

(b)
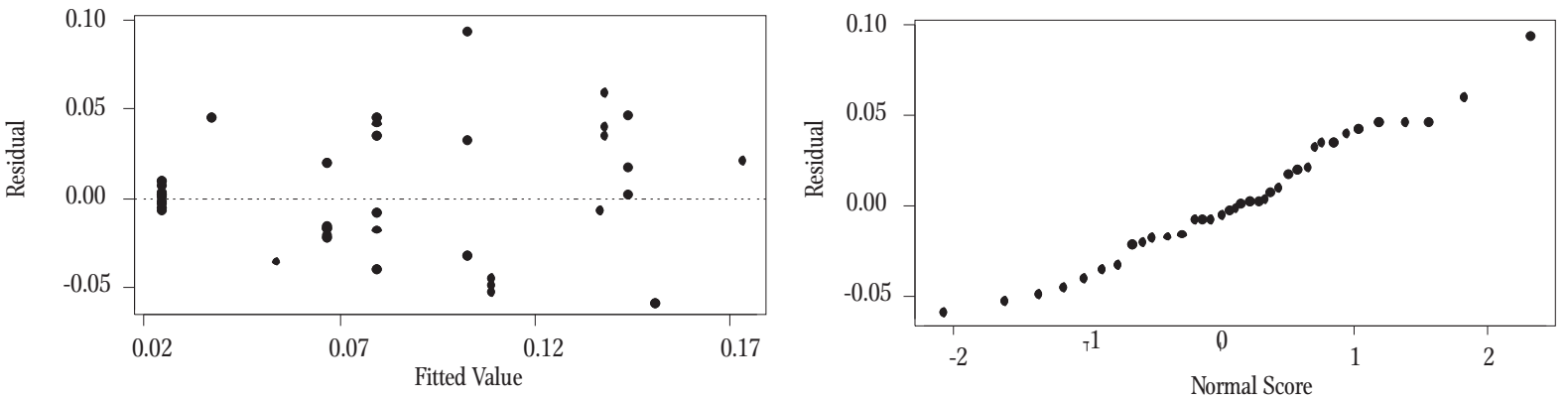

(c)

Figure 2. Plot of residuals vs. fitted values with the normal scores of regression analysis of $A$. mola where GW is a dependent variable and (a) UJ, LJ, HMO, and GL are independent variables, (b) Only GL is an independent variable and (c) UJ, LJ and HMO are independent variables.

values. Of these, GL showed a statistically significant effect when regressed on GW (Table 3a). However, UJ and LJ have no significant effect on GW when regressed together with GL. A plot of residual vs. fitted values in this model exhibited heteroscedasticity, where the residuals explained the positive correlation to the fitted values with normally distributed errors (Fig. 2a). A similar plot with only GL also exhibited the same property (Fig. 2b); however, excluding GL, the plot tended to be homoscedastic in nature with normally distributed errors (Fig. 2c). When each was analyzed separately, these two biometric measurements, along with HMO, significantly determined GW with $56.3 \%$ of variability (Table $3 \mathrm{~b}$ ). GL itself can independently explain $59.9 \%$ of total variability when regressed against GW in A. mola (Table 3c). Similarly, in P. ticto HMO, VMO, and GL explained $57.9 \%$ of variation when regressed on GW. In this species, too, GL showed a statistically significant effect when regressed on GW (Table 4). The plot of residuals vs. fitted values showed strong homoscedasticity at the beginning, but it moved toward heteroscedasticity when the fitted value increased with normally distributed errors (Fig. 3a). A similar plot with GL was strictly limited to heteroscedasticity (Fig. 3b). The VIF values of all the variables were as low as 2.0. E. danricus had three independent variables and when regressed on GW, they explained only $32.5 \%$ of the dependent variable variation with GL showing a statistically significant effect (Table 4). In this species, all the independent variables showed VIF values as low as 3.0. The plot of residual vs. fitted values with and without GL exhibited near heteroscedasticity with normally distributed errors (Fig. 4). 

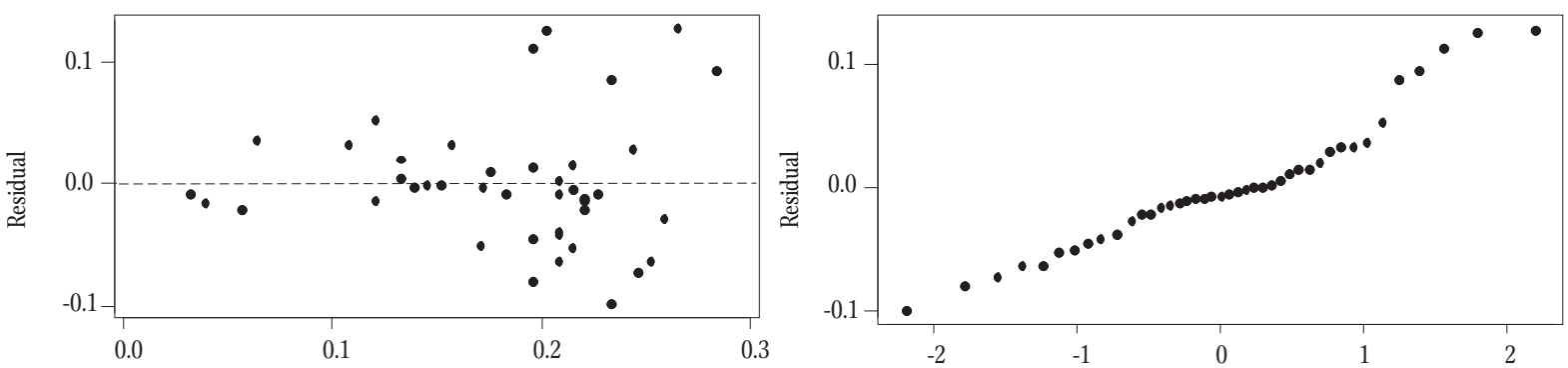

(a)
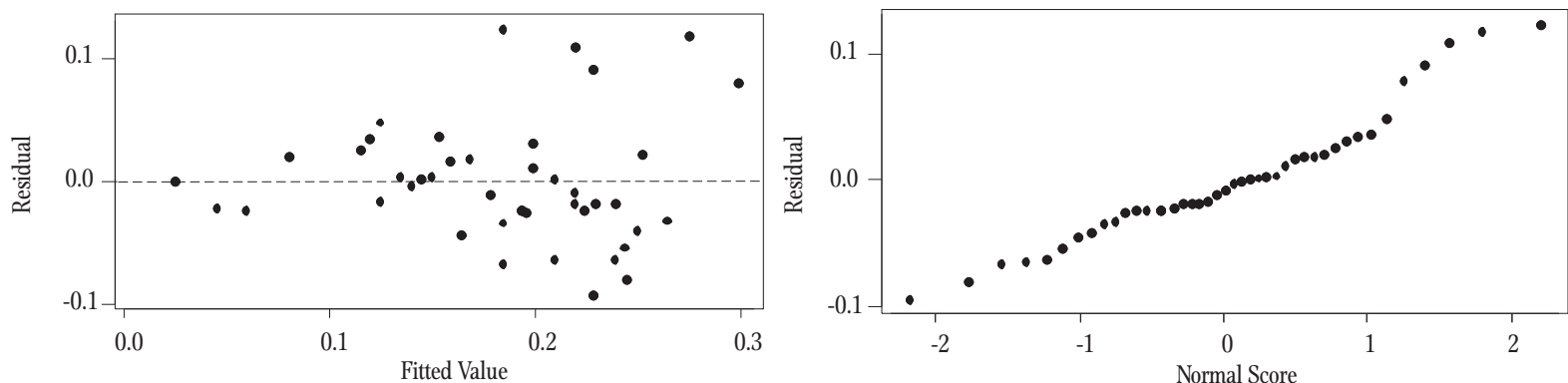

(b)

Figure 3. Plot of the residuals vs. fitted value with the normal scores of regression analysis of the $P$. ticto where GW is the dependent variable and (a) GL is the independent variable and (b) HMO, VMO, and GL are the independent variables.
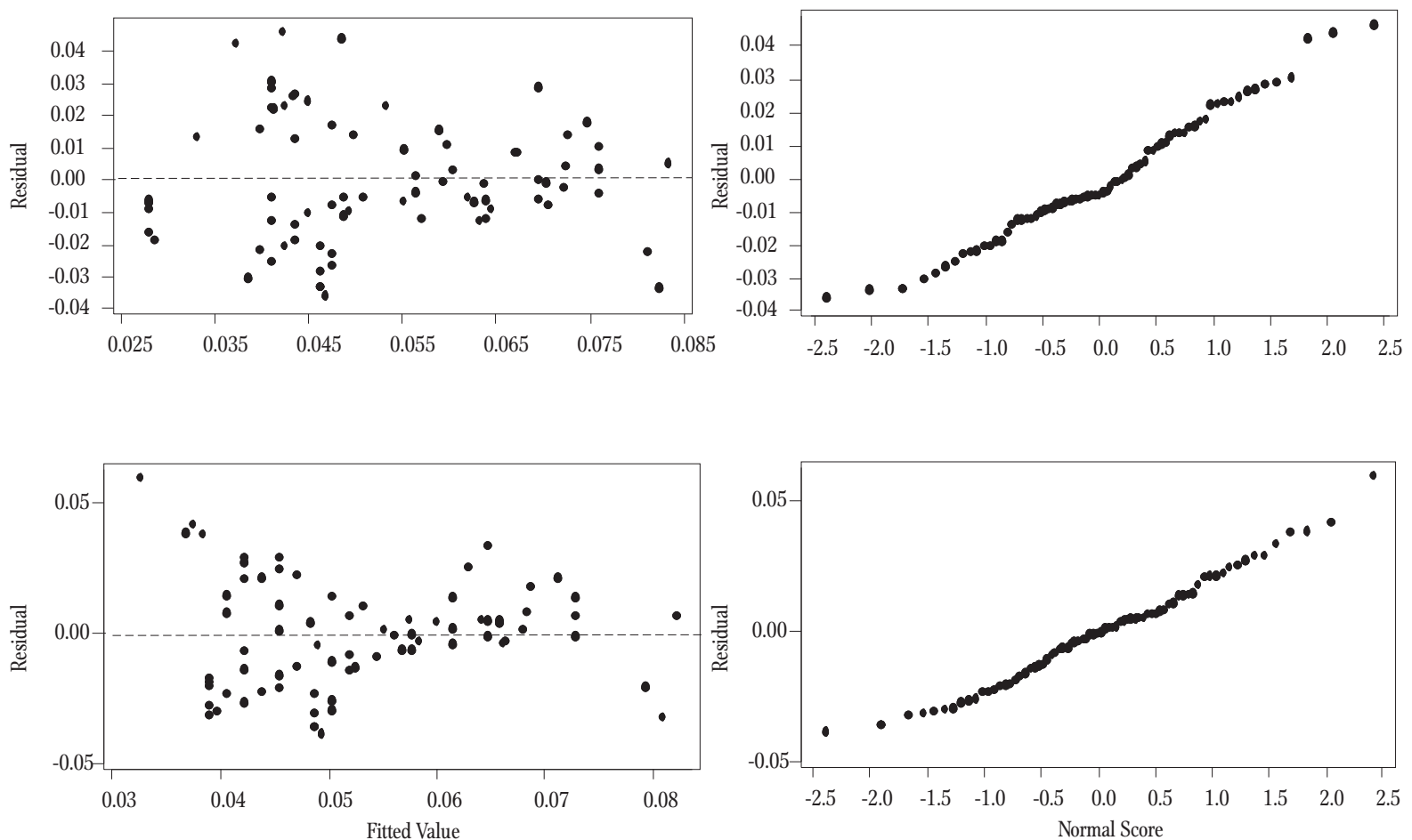

Figure 4. Plot of the residuals vs. fitted value with the normal scores of regression analysis of the E. danricus where GW is the dependent variable and (a) HMO, VMO, and GL are independent variables, and (b) GL is the independent variable. 


\section{Discussion}

\section{Factorial analysis}

The proportion of the total variance explained by factors 1 and 2 is additive, with the second factor contributing less than the preceding one to the variance explained. This occurs as the factors are derived in decreasing order of importance. In the present study, except for $A$. mola, both factors 1 and 2 in E. danricus and $P$. ticto exhibited almost equal variability with all biometric traits. Besides, the Kaiser-Meyer-Olkin measure of sampling adequacy was higher than the recommended value (i.e., >0.6), and Bartlett's test of sphericity was significant $(\mathrm{p}<0.001)$, which indicated that the set of variables are at least adequately related for factor analysis. Further, the correlation analysis explained several sizable correlations (> 0.5) among the biometric traits. Moreover, the communalities were below 1.0, further confirming that each item has some common variance with the other items; thus, it qualified all six variables for factor analysis. In general, component loadings (correlation coefficients) $>0.6$ can be considered in the interpretation of the results (Mahloch 1974). Such loading indicates the highest correlations between the variables and the corresponding factor. Besides the high loading of the variables by means of the correlation coefficients on interpreting a component, the variance of the principal component was also primarily considered for precise interpretation as it provides more information regarding the number of factors to be considered. In all the cases, only factors with eigenvalues $>1.0$ were considered.

In the case of $A$. mola, factor 1 provides information about GW, UJ, LJ, HMO, VMO, and GL. Of these, GL, UJ, and LJ showed the highest positive loading (> 0.90 ) on factor 1 with $63.3 \%$ of the variation of the original data set explained. Factor 2 explained $24.3 \%$ of the total variance of the original data, and only VMO had a high, negative loading on it. The communalities of all these variables were < 1.0 and, therefore, presumably all these variables were described at an acceptable level. In the case of
A. mola, factor analysis clearly indicated that GW was highly correlated to UJ and LJ, followed by GL. VMO showed a strong correlation to factor 2 and, hence, had no effect on the GW of the fish at all. HMO was positively loaded on factor 1 , whereas it was negatively cross-loaded on factor 2 , suggesting an affirmative role on feeding as interpreted by the fish GW. The A. mola has been described recently as a size-selective plankton feeder (Nandi and Saikia 2015), and it can ingest plankton 2-6 $\mu \mathrm{m}$ to a total length of $7 \mathrm{~cm}$, whereas, above that it can ingest plankton up to $12 \mathrm{um}$. Nandi and Saikia (2015) further confirmed that the MA computed following the procedure in Erzini et al. (1997) plays a significant role in size-selective feeding by $A$. mola. Interestingly, according to Erzini et al. (1997), MA is computed from HMO and VMO and the strong loading of HMO explains how morphometry plays a significant role in the feeding behavior of this fish. However, the role of VMO in computing MA in this fish might not be necessary. However, the present factorial analysis revealed that it is not $\mathrm{HMO}$ alone, but that $\mathrm{UJ}$ and $\mathrm{LJ}$ could also strongly determine GW in association with HMO in this fish species. Thus, these two variables, partly aided by HMO, can strongly determine GW and, thereby, the feeding success of the fish. All the variables in factor 2 were negatively loaded, with the highest value assigned to VMO (0.935). GW has a component loading $<0.5$; hence, these variables failed to explain any role in the feeding success of this fish species.

In a similar manner, component loading of the morphometric variables from $P$. ticto on the first two factors explained $84 \%$ of the total variation in the original data. Variables loaded along with GW on factor 1 were GW, HMO, VMO, and GL. These variables showed the highest positive correlation and communalities of $<0.9$. Thus, these variables can be categorized as variables that strongly determine food success. In contrast to A. mola, where UJ and LJ were highly correlated to factor 1 , in $P$. ticto they exhibit high correlation to factor 2 with communalities $<1.0$, but they are not statistically related to GW. Thus, UJ and LJ are considered to be variables that scarcely determine feeding success in P. ticto. 
In E. danricus, the first two factors explained $81.9 \%$ of the total variation in the original data, of which factor 1 and factor 2 explained $41.1 \%$ and $40.8 \%$, respectively, of the total variation. Interestingly, factor 1 had only two variables, UJ and LJ, carrying the highest loading with communalities $<1.0$. Unlike the $A$. mola and $P$. ticto, GW is very poorly loaded on factor 1 . However, it is strongly loaded on factor 2 (communality < 0.7) along with three other variables, i.e., HMO, VMO and GL. The communality for these three variables was $<0.9$. In the case of E. danricus, UJ and LJ were not significant in determining the feeding ability of the fish; hence, they can be categorized as variables that only slightly determine feeding success in this species. The variables loaded on factor 2 correlate strongly among them and can be considered as variables that strongly determine the feeding success of this species.

Factor analysis clearly indicated that the feeding success in the group of small fishes studied is governed by different morphometric variables that vary from species to species. These are, first, UJ, LJ, $\mathrm{HMO}$, and GL for A. mola; second, VMO, HMO, and GL, for E. danricus, and VMO and GL for P. ticto; and third, GL shows the most obvious contribution to GW of these fishes in all instances. It is evident that, in relation to feeding success, all three small fishes exhibit different degrees of morphoecological variation in the mouth in the freshwater habitat. Plasticity in morphology was previously observed in other fishes (Wimberger 1992, Muschick et al. 2011), and this study confirms this phenomenon in small freshwater fishes.

\section{Multiple regression analysis}

Thus, it is evident from the discussion above that a single variable may not uniformly demonstrate (e.g., Ponton and Müller 1990, Erzgini et al. 1997) feeding success in fishes. Species-wise, the morphometric variables that could provide close association with feeding success might vary. In this study, the morphometric variables were reduced using multiple factor analysis, followed by multiple regression analysis to identify how these morphometric variables determined the feeding success in each fish species. A few selective variables which exhibited high loading with GW in factorial analysis as an independent variable were found to explain GW, a dependent variable in the present study. In the regression model of $A$. mola, GL was significantly associated with GW, followed by HMO and LJ. However, UJ, although highly loaded with GW in the factor analysis, showed a coefficient value statistically indifferent to 0 ( $p>0.05$ ); thus, it did not exert any meaningful effect on the model. However, in this regression model the slightly heteroscedastic plot of the residuals vs. the fitted values tended to be homoscedastic when the fitted value increased. In the absence of GL, such heteroscedasticity disappeared, and a homoscedastic plot was formed suggesting that $\mathrm{HMO}, \mathrm{UJ}$, and $\mathrm{LJ}$ were the best morphometric variables to determine feeding success in A. mola. Further, because of the expression of the significant effect on GW with $57 \%$ variability, this regression analysis indicated that feeding success in A. mola could be highly dependent on the measurements of mouth morphometry. While GL might have independently explained almost $60 \%$ of the feeding success over these morphometric measurements, such a relationship could be correct only when the fitted values were high. In P. ticto, although VMO and HMO were highly loaded with GW, they exerted no meaningful effect on GW since their coefficients were not statistically different from $0(p>0.05)$. Interestingly, in this fish species, GL alone exhibited a highly significant association with GW, which confirmed it to be one of the important morphological variables that could determine the feeding success of this fish species. The plot of residuals vs. the fitted values of this regression model exhibited homoscedasticity when the fitted values were high. Thus, in the case of $A$. mola and P. ticto, GL could be a deterministic morphometric variable at an advanced stage of fish growth when the gut reached a considerable length. In the case of $E$. danricus, it was HMO that showed a significant association with GW, followed by GL and VMO. The plot of residual 
vs. fitted values in this model explained a negatively correlated heteroscedastic linear model; however, when GL alone was considered in this model, it could not improve this situation. In E. danricus, the extremely low variability (32.5\%) suggested that some factors other than mouth morphometry could be acting as the deterministic factor for the remaining unexplained portions of the variations in this species.

\section{Mouth morphology and feeding success: How are they related in small fish?}

Mouth morphology describes the feeding plasticity of fish to the habitat (Santos et al. 2011, Sebastian et al. 2011). The present study provides insight to more clearly understand the mouth as a morphological determinant in small fish feeding success. In the studies on the feeding ecology of fish, the mouth area (MA) has been used as an effective morphological determinant, which actually measures the mouth dimensions to explain size-dependent (of prey) feeding success in fishes. Earlier, two such measurements of MA were proposed by Ponton and Müller (1990) and Erzini et al. (1997). Ponton and Müller (1990) actually measured the gape size (GS), which, in other words, describes the mouth area of the fish. They hypothesized that the gape size in a fish at maximum $90^{\circ}$ orientation can be obtained using UJ $\times \sqrt{ } 2$. Erzini et al. (1997) used half the product of HMO, $\mathrm{VMO}$, and $\Pi$ to explain the effective mouth area of fish. Thus, the computation of GS and MA are based on either UJ or HMO and VMO. As the variables responsible for feeding success in these small fish species are clear from this study, the practices of determining feeding success can be reviewed, at least for small fishes, with an emphasis on the selection of the actually functional morphometric measurements from the head or other body regions. For example, VMO and HMO, as in the study of Erzini et al. (1997) are not the only determinants in the feeding success of A. mola; UJ and LJ are also equally important. Similarly, in P. ticto, VMO may better explain the feeding efficiency of the fish.
Therefore, while considering mathematical models for estimating mouth areas to describe feeding habits in fish, emphasis must not be placed only on food size, but also on the orientation of the food during ingestion. As aquatic organisms, fish feed in a three dimensional plane, which means that it is possible for prey to be ingested either length-wise or width-wise or both length- and width-wise. To some extent, the nature of variables can suggest such a feeding mode in fish. There is a strong possibility that the lengths of the upper and lower jaws, and not HMO and VMO, combinatorially confer a kind of directional effect on the food ingestion capacity of the fish. During the larval fish stage, prey-size dependent feeding preferences were reported to be gape-limited by jaw length (Conley and Hopkins 2004, Truemper and Lauer 2005, Makrakis et al. 2008). These authors observed that the largest size range of prey was ingested by the larvae with the largest jaws, and the smallest prey by the larvae with the smallest jaws. Further, the gape limitation by jaw length may affect the length-wise ingestion of prey, thereby describing a kind of one-dimensional gape limitation (either length- or width-wise). However, the horizontal and vertical mouth openings may set a two-dimensional gape limitation on feeding (both length- and width-wise). Thus, $P$. ticto may have a different feeding strategy when compared with $A$. mola. In this situation, the feeding success based on MA or GS might overlook the true explanation when sharply defined measurements are not actually included in the analysis.

Similarly, the feeding habit of all these fishes could be somewhat better explained by their gut length. The hypothesis of having a higher gut weight at longer gut lengths could be explained as the ability of accommodating maximum food content in longer guts. It is established that a larger stomach capacity resulting from an ontogenic shift may result in active feeding relationships in fishes (Gosch et al. 2009). However, a longer gut length in the absence of a true stomach may also explain a similar feeding strategy in fishes. As in the case of the predator fishes where the larger stomach volume induces plasticity in feeding (Gill and Hart 1998), longer stomachs in small 
fishes with high TL may serve a similar purpose during active feeding.

\section{Conclusion}

Small herbivorous and microphagous fishes ingest plankton that are static in nature and, therefore, as in carnivorous fishes, the body length or head depth may not be as important as other morphometric adjustments in the mouth. In this context, the hypothesis that jaw length and mouth openings could explain their feeding success could be correct. In particular, in the case of $A$. mola, such a hypothesis could be adopted.

This is obvious from several prior studies on herbivorous fishes that they are often equipped with a long alimentary canal without a distinct stomach (Dasgupta 2001, German and Horn 2006). The carnivorous nature of fishes can be explained by the short alimentary canal in association with a well-developed stomach (Dasgupta 2000, Naguib et al. 2011). The fishes studied here are mainly microphagous with gut lengths long enough to explain their herbivorous feeding behavior. The new feature that the present study suggests is that the longer gut length of these fishes may also determine their feeding success. Other than an enhanced gut area in a longer gut in these fishes, there may be several other underlying factors, physical, endocrinological, or physiological, associated with the gut length of the fish that might contribute to the feeding behavior of these fishes. Further studies on otoliths can also contribute to our understanding of the long-term feeding success (Pepin et al. 2015) of these species.

Acknowledgments. The authors are highly indebted to financial support by the University Grants Commission, New Delhi through the UGC-BSR fellowship.

Author contributions. S.K.S. conceived of the research work, supervised the study, and prepared the text; S.N. performed the study, collected data, and analyzed results.

\section{References}

Carroll A.M., Wainwright P.C., Huskey S.H., Collar D.C., Turingan R.G. 2004 - Morphology predicts suction feeding performance in centrachid fishes - J. Exp. Biol. 204: 3873-3881.

Chattopadhyay S., Nandi S., Saikia S.K. 2014 - Mouth morphometry and architecture of freshwater cat fish Mystus vittatus Bloch (1974) (Siluriformes, Bagridae) in relation to its feeding habit - J. Sci. Res. 6: 169-174.

Conley W.J., Hopkins T.L. 2004 - Feeding ecology of Lanternfish (Pisces: Myctophidae) larvae: prey preferences as a reflection of morphology - B. Mar. Sci. 75: 361-379.

Dabrowski K., Bardega R. 1984 - Mouth size and predicted food size preferences of larvae of three cyprinid fish species - Aquaculture 40: 41-46.

Dasgupta M. 2000 - Adaptation of the alimentary tract to feeding habits in four species of fish of the genus Channa - Indian J. Fish. 47: 265- 269.

Dasgupta M. 2001 - Morphological adaptation of the alimentary canal of four Labeo species in relation to their food and feeding habits - Indian J. Fish. 48: 255-257.

Dean M.N., Motta P.J. 2004 - Feeding behavior and kinematics of the lesser electric ray, Narcine brasiliensis (Elasmobranchii: Batoidea) - Zoology 107: 171-189.

Erzini K., Gonçalves J.M.S., Bentes L., Lino P.G. 1997 - Fish mouth dimensions and size selectivity in a Portuguese longline fishery - J. Appl. Ichthyol. 13: 41-44.

German D.P., Horn M.H. 2006 - Gut length and mass in herbivorous and carnivorous prickleback fish (Teleostei: Stichaeidae): ontogenic, dietary, and phylogenetic effects - Mar. Biol. 148: 1123-1134.

Gill A.B., Hart P.J.B. 1998 - Stomach capacity as a directing factor in prey size selection of three-spined stickleback J. Fish Biol. 53: 897-900.

Gosch N.J.E., Pope K.L., Michaletz P.H. 2009 - Stomach capacities of six freshwater fishes - J. Freshw. Ecol. 24: 645-649.

Hugueny B., Pouilly M. 1999 - Morphological correlates of diet in an assemblage of West African freshwater fishes J. Fish Biol. 54: 1310-1325.

Mahloch J.L. 1974 - Multivariate techniques for water quality analysis - J. Environ. Eng. Div. Amer. Soc. Civil Eng. 100: 1119-1132.

Makrakis M.C., Nakatani N., Bialetzki A., Gomess L.C., Sanchess P.V., Baumgartner G. 2008 - Relationship between gape size and feeding selectivity of fish larvae from a Neotropical reservoir - J. Fish Biol. 72: 1690-1707.

Mamun A., Tareq K.M.A., Azadi M.A. 2004 - Food and feeding habit of Amblypharyngodon mola (Hamilton) from 
Kaptai Reservoir, Bangladesh - Pak. J. Biol. Sci. 7: 584-588.

Mondol M.R., Nahar D.A., Dewan S., Rahaman M., Jasmine S., Hossain Y. 2013 - Food and feeding habits of the Molacarplet Amblypharyngodon mola (Hamiton, 1822) in rice field ecosystem with consideration of water quality parameters - Our Nature 11: 61-75.

Muschick M., Barluenga M., Salzburger W., Meyer A. 2011 Adaptive phenotypic plasticity in the Midas cichlid fish pharyngeal jaw and its relevance in adaptive radiation - BMC Evol. Biol. 11: 116. doi: 10.1186/1471-2148-11-116.

Naguib S.A.A., Shabaka H.A.E.I., Ashour F. 2011 - Comparative histological and ultrastructural studies on the stomach of Schilbe mystus and the intestinal swelling of Labeo niloticus - J. Am. Sci. 7: 251-263.

Nandi S., Saikia S.K. 2015 - Size selective feeding on phytoplankton by two morphogroups of small freshwater fish Amblypharyngodon mola - J. Fish Biol. doi: 10.1111/jfb.12706.

Nilsson P.A., Brönmark C. 2000 - Prey vulnerability to a gape-size limited predator: behavioural and morphological impacts on northern pike piscivory - Oikos 88: 539-546.

Pepin P., Robert D., Bouchard C., Dower J.F., Falardeau M., Fortier L., Jenkins G.P., Leclerc V., Levesque K., Llopiz J.K. Meekan M.G., Murphy H.M., Ringuette M., Sirois P., Sponaugle S. 2015 - Once upon a larva: revisiting the relationship between feeding success and growth in fish larvae - ICES J. Mar. Sci. 72: 359-373.

Piet G.J. 1998 - Ecomorphology of a size-structured tropical freshwater fish community - Environ. Biol. Fish. 51: 67-86.
Ponton D., Müller R. 1990 - Size of prey ingested by whitefish, Coregonus sp., larvae. Are Coregonus larvae with gape-limited predators? - J. Fish Biol. 36: 67-72.

Ross S.T. 1986 - Resource partitioning in fish assemblages: a review of field studies - Copeia 1986: 352-388.

Santos A.B.I., Camilo F.L., Albieri R.J., Araújo F.G. 2011 Morphological patterns of five fish species (four characiforms, one perciform) in relation to feeding habits in a tropical reservoir in south-eastern Brazil - J. Appl. Ichthyol. 2011: 1-5.

Sebastian H., Inasu N.D., Tharakan J. 2011 - Comparative study of the mouth morphology and diet of three co-occurring species of sliverbellies along the Kerala coast - J. Mar. Biol. Ass. India 53: 196-201.

Sen T.K. 1985 - Records of the Zoological Survey of India Zoological Survey of India, Calcutta, India.

Talwar P.K., Jhingran A.G. 2001 - Inland Fisheries of India and Adjacent Countries - Oxford and IBH, New Delhi, India.

Truemper H.A., Lauer T.E. 2005 - Gape limitation and piscine prey size-selection by yellow perch in the extreme southern area of Lake Michigan, with emphasis on two exotic prey items - J. Fish Biol. 66: 135-149.

Wainwright P.C., Richard B.A. 1995 - Predicting patterns of prey use from morphology of fishes - Environ. Biol. Fish. 44: 97-113.

Wikramanayake E.D. 1990 - Ecomorphology and biogeography of a tropical stream fish assemblage: evolution of assemblage structure - Ecology 71: 1756-1764.

Wimberger P.H. 1992 - Plasticity of fish body shape, the effects of diet, development, family and age in two species of Geophagus (Pisces: Cichlidae) - Biol. J. Linn. Soc. 45: 197-218. 